INDO GLOBAL JOURNAL OF

PHARMACEUTICAL SCIENCES

ISSN 2249- 1023

\title{
Status of Ambient Air Quality of Topographical Different Cities
}

\author{
Parul Chauhan ${ }^{1}$, Pammi Gauba ${ }^{1}$, Sanjeev Aggarwal ${ }^{2}$, Sanghita Roy Chaudhary ${ }^{2}$ \\ ${ }^{1}$ Department of Biotechnology, Jaypee Institute of Information Technology, Noida, U.P., India \\ ${ }^{2}$ PAMS Division, Central Pollution Control Board, Delhi, India \\ Address for Correspondance: Pammi Gauba, pammigauba@hotmail.com
}

\begin{abstract}
Keywords Topographical and Meteorological Conditions; Urbanization; Industrialization; Particulate Matter; Ambient Air Quality; NAAQS.
\end{abstract}

\begin{abstract}
Air pollution is a solemn environmental concern around the whole world. Over last decades increase in industrialization, urbanization and rapid growth in population led to retrogression environmental conditions. Due to challenge of strengthening the economy of country, India is facing issues in protecting its environment as 2014 WHO report India ranked 9 in most polluted countries in the world. According to the WHO report $80 \%$ of urban population is exposed to the air quality levels which is exceeded the standard limits. Major polluted cities in India contains high level criteria of pollutants like Sulphur Dioxide(SO2), Nitrogen Dioxide(NO2), Particulate Matter(PM), Greenhouse gases, Ozone precursors and aerosols etc. which deteriorate the environment. In this assessment 3 air pollutants are monitored for air quality evaluation from 7 topographical different cities (Chandigarh, Ahmedabad, Bhopal, Chennai, Bay of Bengal, Shillong, Thiruvendrum) which are SO2, NO2 and PM10.There are various health risks of these air pollutants, NO2Lung irritation, higher respiratory illness rates, airway resistance chest tightness and discomfort,SO2- Heart and lung diseases, Chronic bronchitis, pulmonary emphysema, cancer.PM10- Pneumonia, cardiac diseases, cancer, eye irritation, respiratory problems. The air quality generated data at monitoring stations are entered into the data bank of CBCP -EDB (environmental data bank) in this assessment data from 2005 to 2015 is compiled and analyzed. Study shows fluctuating trendin level of pollutants from 2005 to 2015 where $\mathrm{SO} 2$ and NO2 are more or less stable and coming under the NAAQS limits whereas PM10 shows increment in its level up to 2013, then slightly decrement in 2014 and 2015. Government has many policies and control strategies to improve air quality but there is need to focus on non-exhaust emission including municipal waste and biomass burning, rapid increase in vehicles, decrease in forest area etc.Topographical and meteorological conditions also plays an important role in increment or decrement in air pollution rate over the areas. (C) 2016 iGlobal Research and Publishing Foundation. All rights reserved.
\end{abstract}

Conference Proceedings: International Conference on Advances in Plant and Microbial Biotechnology (PMB2017); JIIT, Noida: February 02-04, 2017

Indo Global Journal of Pharmaceutical Sciences( ISSN 22491023 ; CODEN- IGJPAI; NLM ID: 101610675) indexed and abstracted in EMBASE(Elsevier), SCIRUS(Elsevier),CABI, CAB Abstracts, Chemical Abstract Services(CAS), American Chemical Society(ACS), Index Copernicus, EBSCO, DOAJ, Google Scholar and many more. For further details, visit http://iglobaljournal.com 